Supporting information for

Fluorination of an $N, N, N^{\prime}, N^{\prime}$ - Tetraphenylbenzidine Derivative as a Dopant-Free Hole-Transporting Material for Moisture-resistant Perovskite Solar Cells

Youngju Bae ${ }^{\dagger}$, Lian $\mathrm{Li}^{\dagger}$, Ke Yang ${ }^{\dagger}$, Ravi Mosurkal§*, Jayant Kumar ${ }^{\dagger *}$

$\dagger$ Center for Advanced Materials and Department of Physics and Applied Physics, University of Massachusetts Lowell, Lowell, MA 01854 USA (e-mail: Jayant Kumar@ uml.edu).

$\S$ Bio-Science and Technology Team, SPO Directorate, U.S. Army CCDC Soldier Center, Natick, MA 01760, USA (e-mail: ravi.mosurkal.civ@mail.mil).

\title{
Materials and Instruments
}

\section{Materials}

All commercially available starting materials for TPB-2F synthesis were used as received without further purification. Palladium on carbon $(\mathrm{Pd} / \mathrm{C})$, tris(dibenzylideneacetone) dipalladium(0), cetyltrimethylammonium $\quad$ bromide $\quad(\mathrm{CTAB}), \quad$ tris $(1,1-$ dimethylethyl)phosphine $\left(t \mathrm{Bu}_{3} \mathrm{P}\right)$, sodium tert-butoxide, sodium formate, sodium hydroxide, 4-bromo-2-fluoroaniline, 4-bromoanisole, bis(trifluoromethane)sulfonamide lithium salt (LiTFSI), dimethylformamide (DMF), dimethyl sulfoxide (DMSO), chlorobenzene (CB) and isopropyl alcohol (IPA) were purchased from Sigma Aldrich. Lead iodide $\left(\mathrm{PbI}_{2}\right)$ and $N, N, N^{\prime}, N^{\prime}$-tetrakis(4-methoxyphenyl)benzidine were acquired from TCI Chemicals. Fluorine doped tin oxide (FTO) coated glass slides $(2.2 \mathrm{~mm}, \sim 13$ ohm/square) were also purchased from Sigma Aldrich.

\section{Instruments}


${ }^{1} \mathrm{H}$ NMR, ${ }^{13} \mathrm{C}$ NMR and ${ }^{19} \mathrm{~F}$ NMR spectra were obtained using a JEOL ECZ 400 spectrometer. The chemical shifts were recorded against TMS standard. LC-MS spectra were obtained with a Shimadzu 8040 mass spectrometer. UV/vis absorption spectra were measured through a PerkinElmer Lambda 9 spectrophotometer. Photoluminescence was acquired with a PerkinElmer LS 55 luminescence spectrometer excited at $350 \mathrm{~nm}$ for TPB2F film and at $480 \mathrm{~nm}$ for perovskite and HTM coated perovskite films, respectively. Cyclic voltammetry measurement was obtained using a three-electrode configuration. Platinum, $\mathrm{Ag} / \mathrm{AgCl}$ and Pt-wire were used as the working electrode, reference electrode and counter electrode, respectively. Current-voltage (I-V) characteristics of the PSCs were obtained using a Keithley 2400 digital SourceMeter controlled by a personal computer under a standard AM 1.5G solar illumination at 1 sun intensity (Abet Technologies Sun 3000 Class AAA solar simulator). The incident photon-to-current conversion efficiency (IPCE) was recorded using an Abet Technologies AB6000 QE system.

\section{Synthesis and characterization of TPB-2F}

\section{A. Synthesis of bis(2-fluoroaniline) (1) ${ }^{1}$}

Sodium hydroxide was dissolved in water. Sodium formate, 4-bromo-2-fluoroaniline, cetyltrimethylammonium bromide, and $10 \%$ palladium on charcoal were added to the reaction solution. The reaction mixture was stirred and refluxed for $4 \mathrm{hrs}$. Afterwards, another batch of sodium formate was added and the reaction mixture was further stirred at $90{ }^{\circ} \mathrm{C}$ for $20 \mathrm{hrs}$. After cooling down to room temperature, the reaction mixture was filtrated and the residual solids were washed with ethyl acetate. The filtrate was washed with water twice, followed by drying with sodium sulfate. The organic layer was evaporated using a 
rotary evaporator to obtain crude mixture. The crude product was purified by silica column chromatography, using ethyl acetate and hexanes (30:70) as eluents. Evaporation of eluting solvents provides desired product as a yellowish powder (54\% yield). ${ }^{1} \mathrm{H} N \mathrm{NR}\left(\mathrm{CD}_{3} \mathrm{CN}\right.$, ppm, $400 \mathrm{MHz}), \delta=7.21(\mathrm{~d}, 2 \mathrm{H}), 7.19-7.13(\mathrm{dd}, 2 \mathrm{H}), 5.84-6.80(\mathrm{dd}, 2 \mathrm{H}), 4.19(\mathrm{~s}, 4 \mathrm{H}) .{ }^{13} \mathrm{C}$ NMR $\left(\mathrm{CD}_{3} \mathrm{CN}, \mathrm{ppm}, 100 \mathrm{MHz}\right), \delta=153.55,151.67,135.48,135.38,130.90,123.05$, 123.03, 118.32, 117.90, 117.86, 113.61, 113.46. ${ }^{19} \mathrm{~F}$ NMR $\left(\mathrm{CD}_{3} \mathrm{CN}, \mathrm{ppm}, 100 \mathrm{MHz}\right), \delta=$ 130.97. FT-IR wavenumber $\left(\mathrm{cm}^{-1}\right)=\left(-\mathrm{NH}_{2}\right) 3421,3305,3199,(\mathrm{C}=\mathrm{C}) 1648,1576,1502$, (C-F) 1284, 1205.

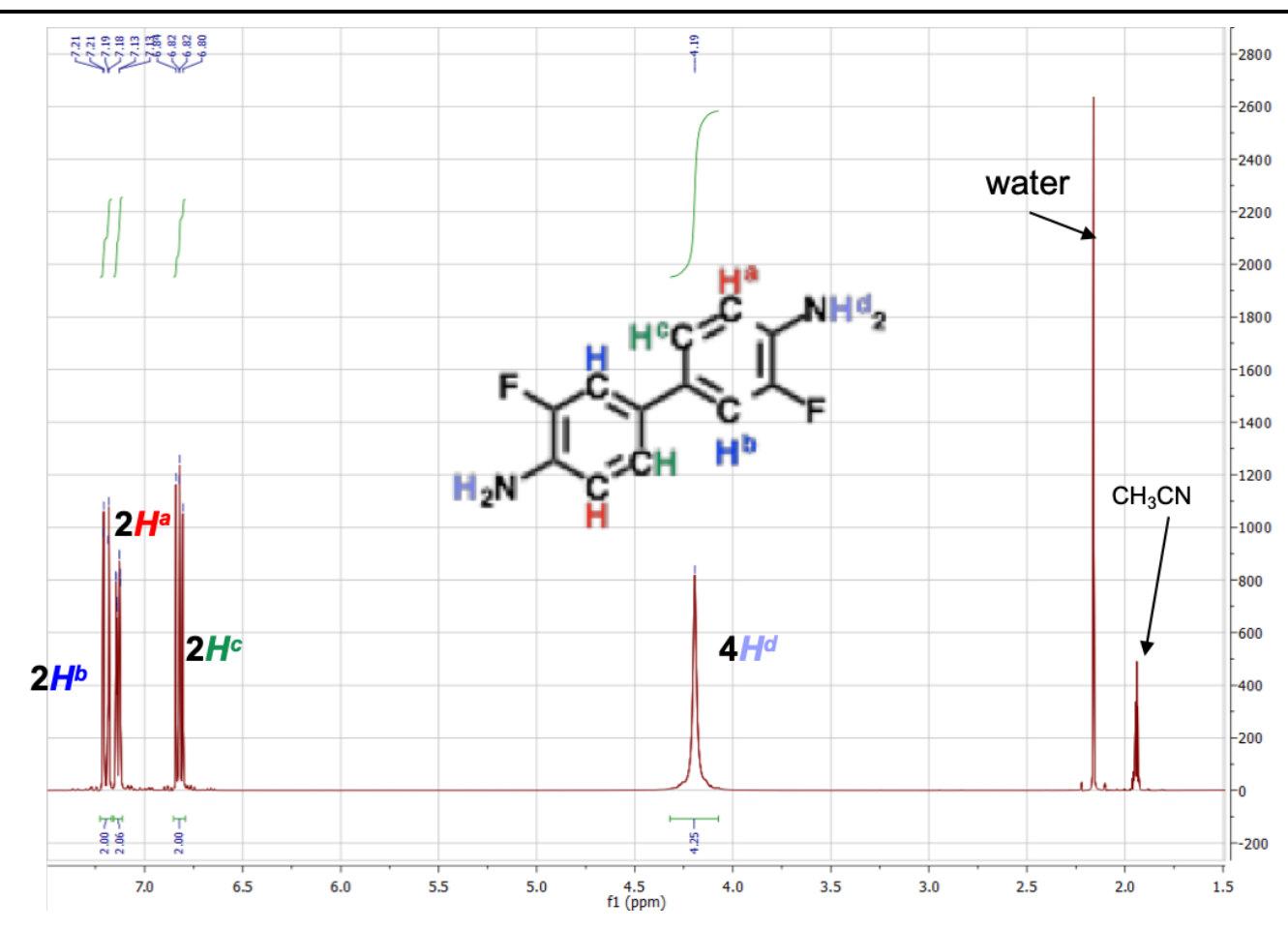

Figure S1. ${ }^{1} \mathrm{H}$ NMR spectrum of bis(2-fluoroaniline) (1). 

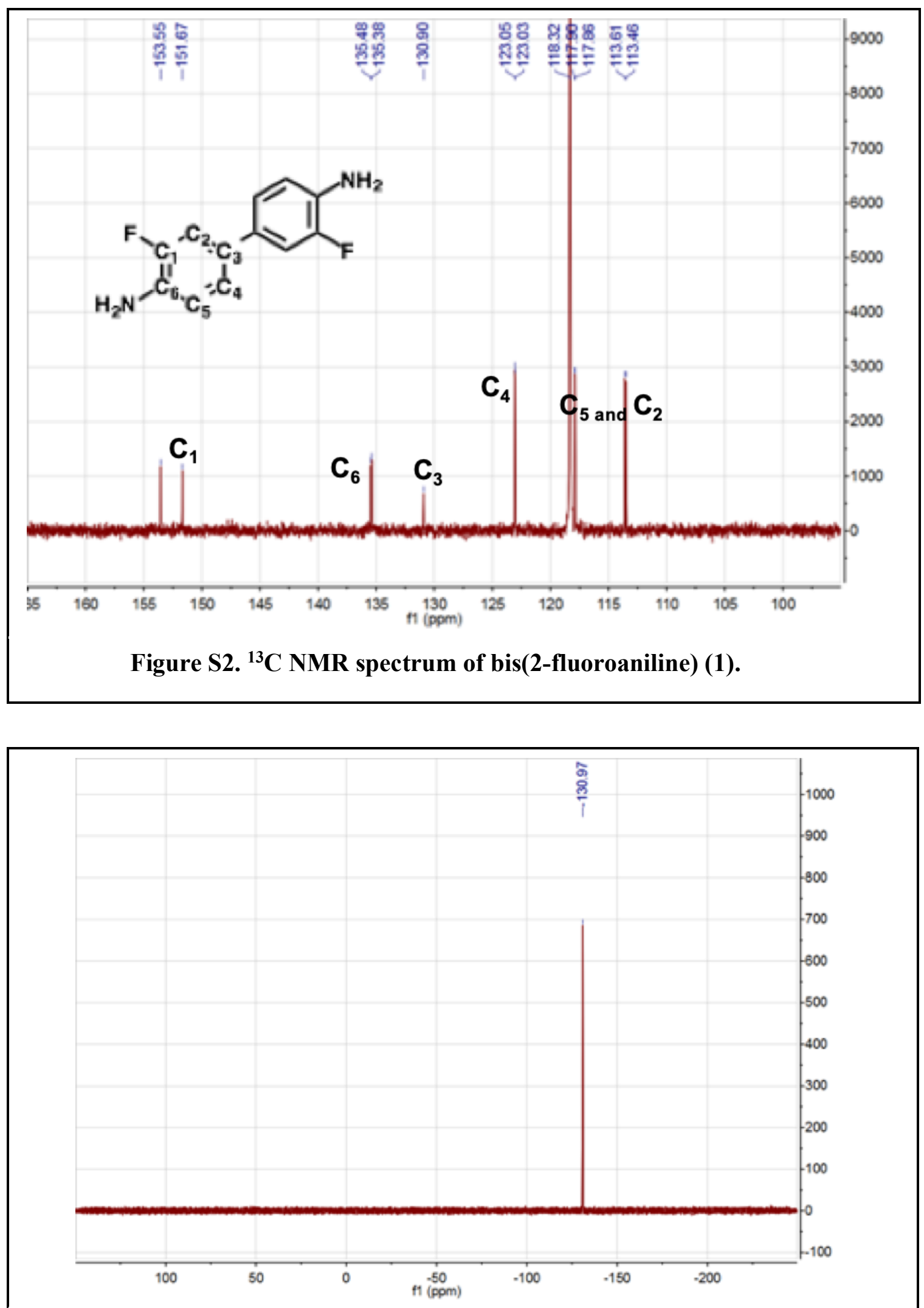

Figure S3. ${ }^{19}$ F NMR spectrum of bis(2-fluoroaniline) (1). 


\section{B. Synthesis of TPB-2F}

TPB-2F molecule was synthesized by Buchwald-Hartwig coupling reaction between bis(2-fluoroaniline) and 4-bromoanisole in the presence of sodium tert-butoxide and tritert-butyl phosphine in toluene solution. Toluene was evaporated then reaction crude was dissolved in ethyl acetate and water. Water layer was extracted with ethyl acetate three times, dried over $\mathrm{Na}_{2} \mathrm{SO}_{4}$. Crude was prepared as slurry to be purified by silica gel chromatography with $10 \%$ ethyl acetate in hexanes, providing the product at $80 \%$ yield. ${ }^{1} \mathrm{H}$ NMR $\left(\mathrm{CD}_{3} \mathrm{CN}, \mathrm{ppm}, 400 \mathrm{MHz}\right) \delta=7.39-7.33(\mathrm{q}, \mathrm{d}, 4 \mathrm{H}), 7.06-7.02(\mathrm{t}, 2 \mathrm{H}), 6.93-6.90$ (m, 8H), 6.86-6.83 (m, 8H), $3.75(\mathrm{~s}, 12 \mathrm{H}){ }^{13} \mathrm{C}$ NMR $\left(\mathrm{CD}_{3} \mathrm{CN}, \mathrm{ppm}, 100 \mathrm{MHz}\right) \delta=159.84$, 155.51, 154.91, 141.22, 135.82, 134.99, 127.58, 124.27, 122.74, 115.20, 114.62, 55.56. FT-IR wavenumber $\left(\mathrm{cm}^{-1}\right)=($ methoxy C-H) 2831, (C=C) 1504, (C-F) 1239, (C-O) 1033. In LC-MS analysis, 645 was calculated, and $644(\mathrm{M}+)$ was found.

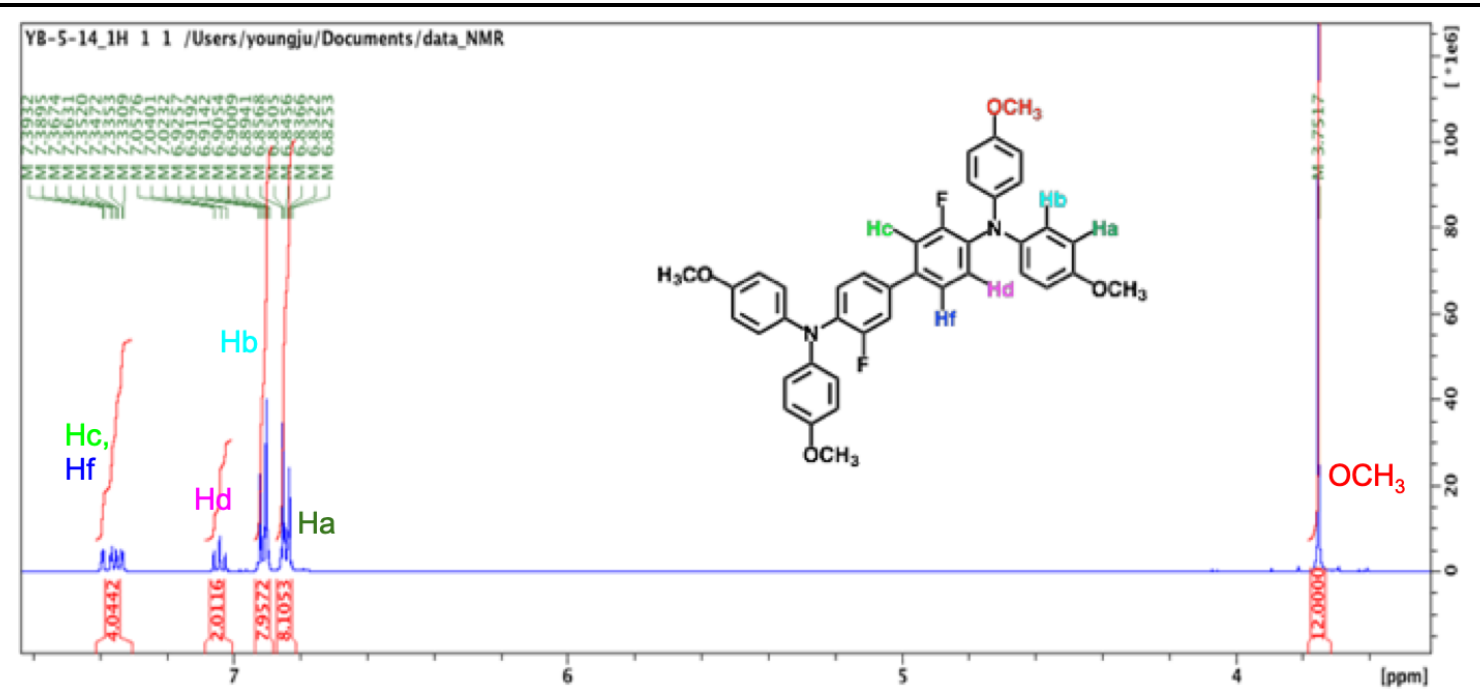

Figure S4. ${ }^{1} \mathrm{H}$ NMR spectrum of TPB-2F. 


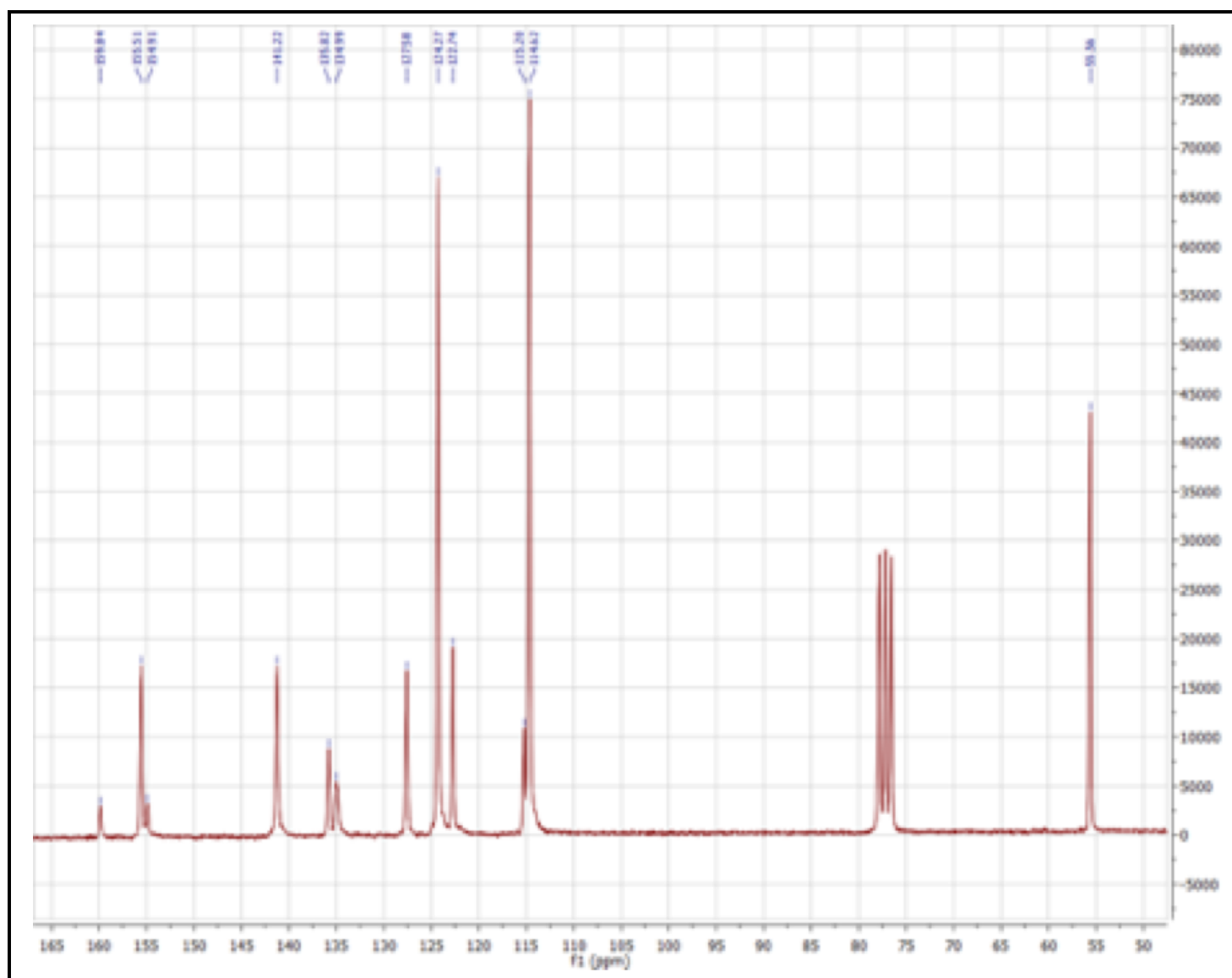

Figure S5. ${ }^{13} \mathrm{C}$ NMR spectrum of TPB-2F.

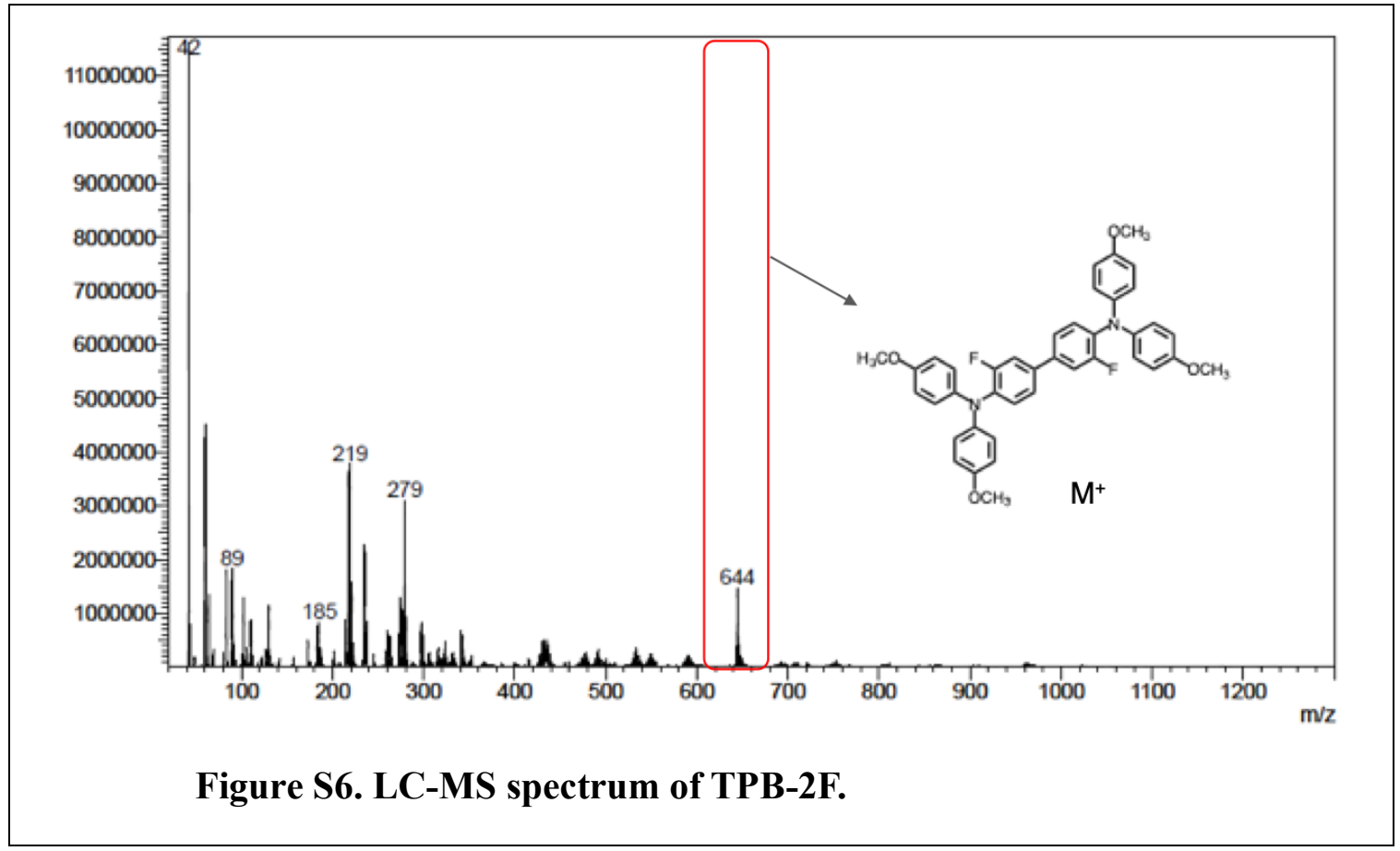


(a)

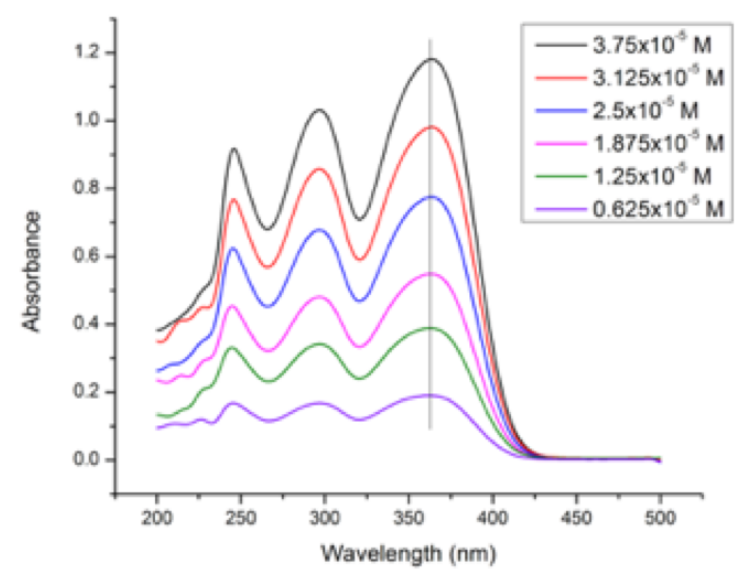

(b)

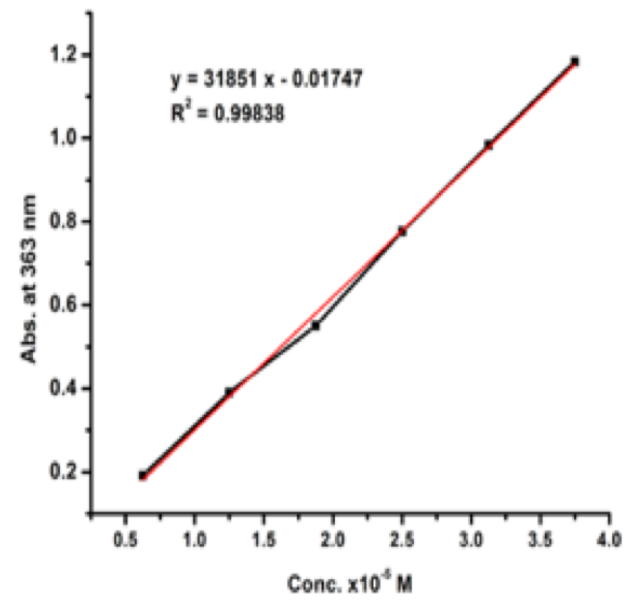

Figure S7. (a) UV/vis absorption spectra of TPB-2F in chloroform at various concentrations, and (b) the extinction coefficient at $363 \mathrm{~nm}$ as a function of the concentration.

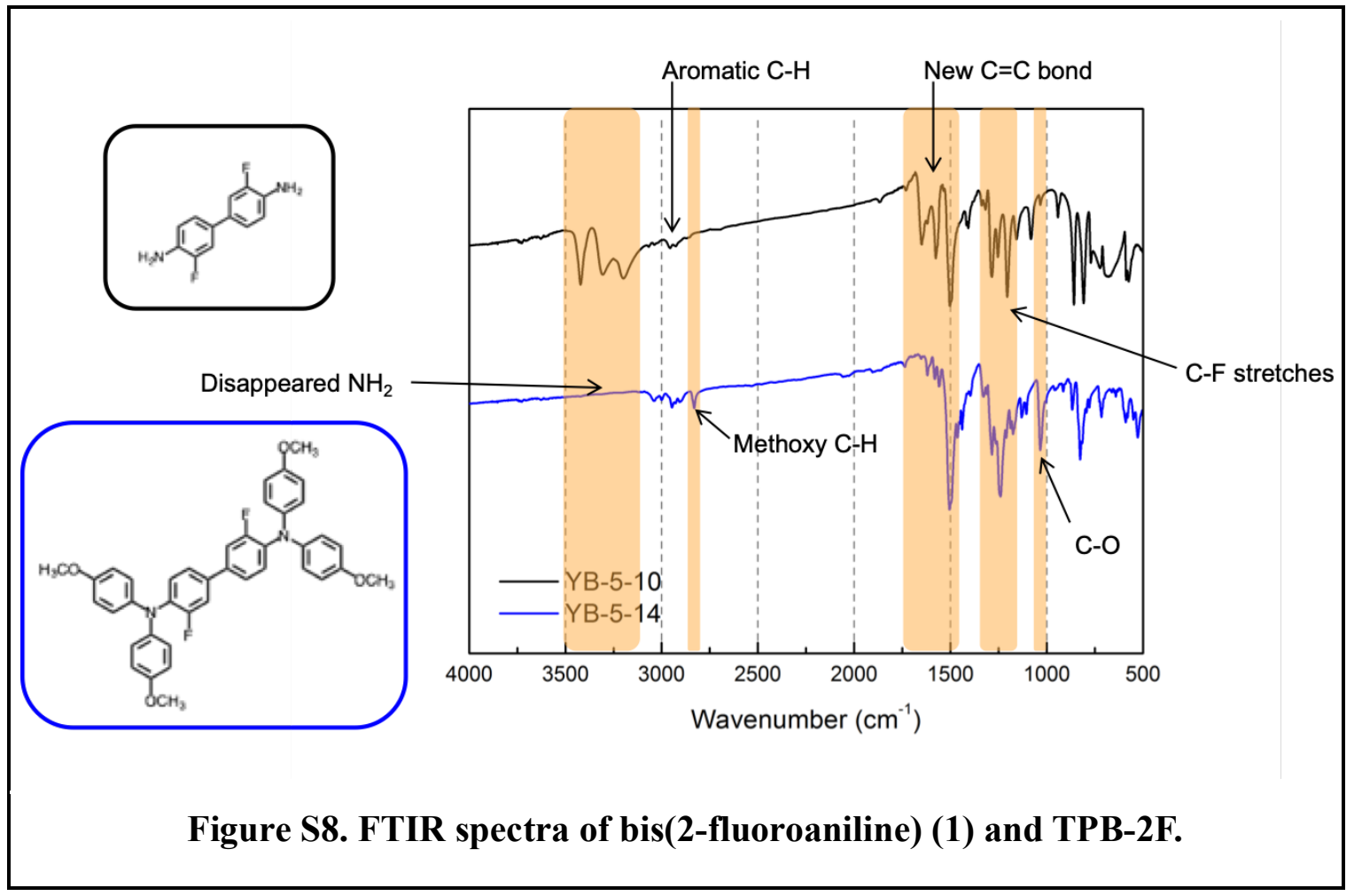




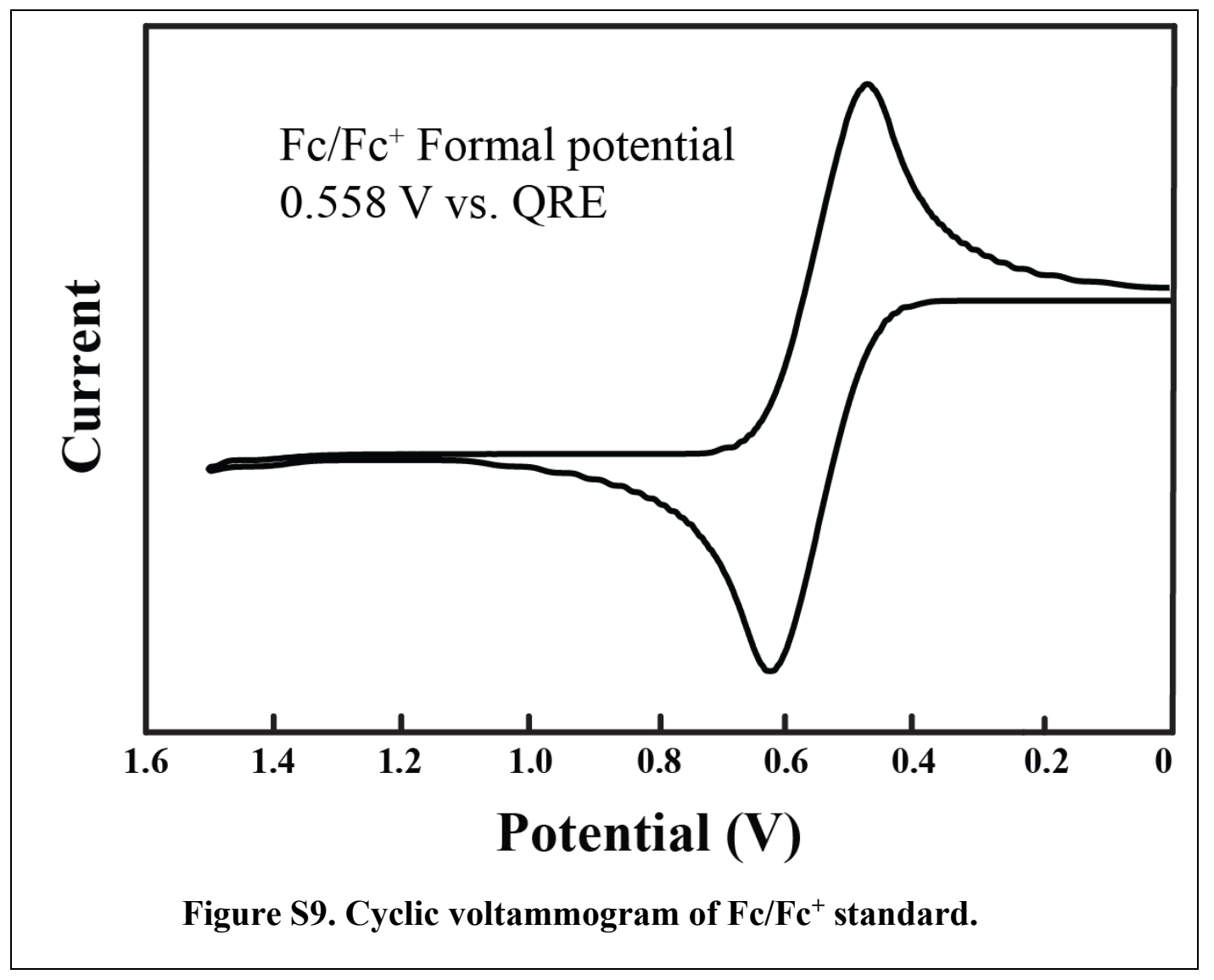




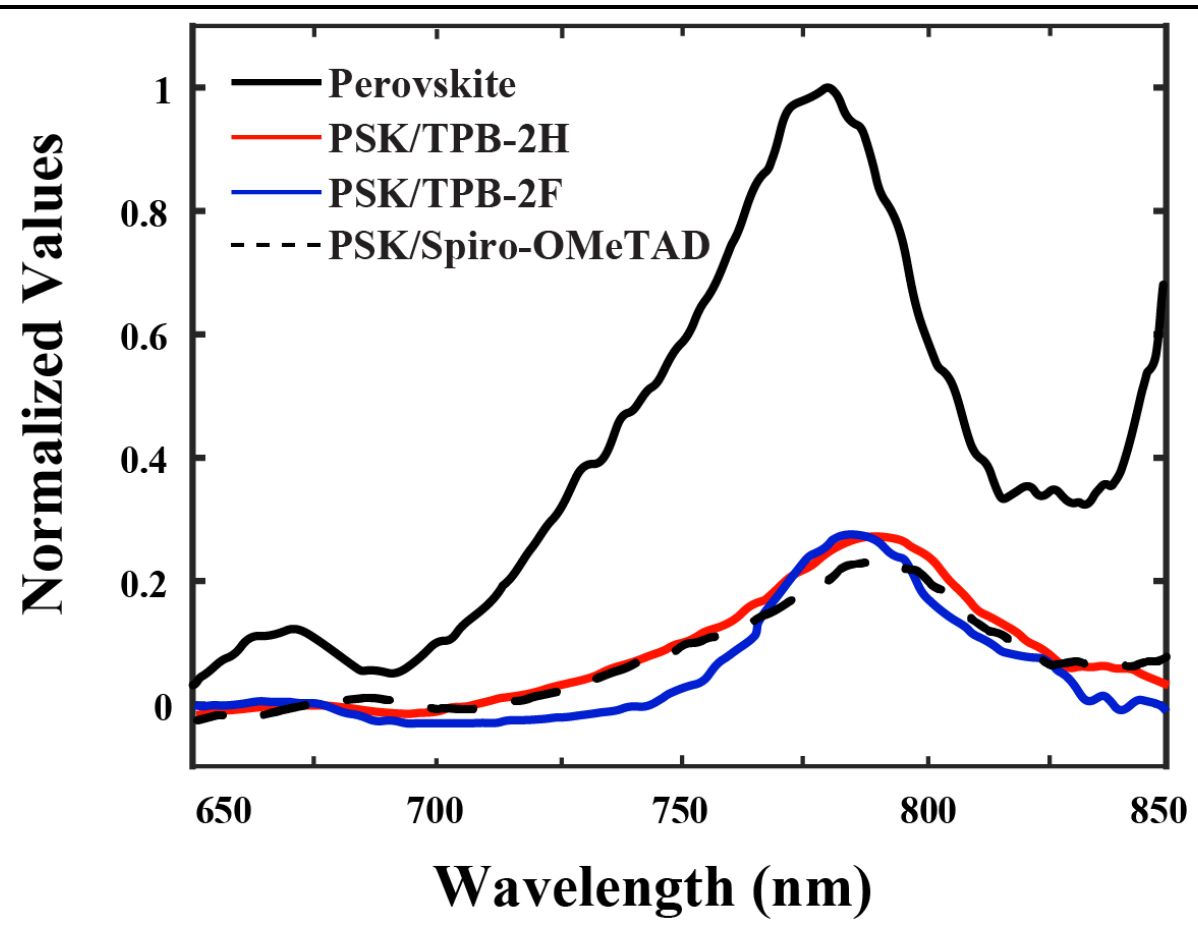

Figure S10. Steady-state PL spectra of the perovskite and perovskite/HTMs films.

\section{Time-resolved Photoluminescence}

The time-resolved photoluminescence (TRPL) experiments were carried out with a home-built system. The perovskite films were prepared following the procedures described earlier. The synthesized fluorinated TPB-2F, the control molecule (TPB-2H) and the commonly used HTM, spiro-OMeTAD were spin-coated on top of the perovskite films. A nitrogen laser (operating at $337 \mathrm{~nm}$ with a pulse-width of $3.5 \mathrm{~ns}$ ) was used as the excitation light source. The energy of the laser pulse was adjusted to be about $10 \mu \mathrm{J}$. A photomultiplier tube (PMT, with a rise time of $2 \mathrm{~ns}$ ) was utilized to detect the TRPL signals. An interference filter centered around $775 \mathrm{~nm}$ was mounted in front of the PMT. 
The TRPL signals were then viewed and captured on a $200 \mathrm{MHz}$ digital oscilloscope (rising time around $2 \mathrm{~ns}$ ).

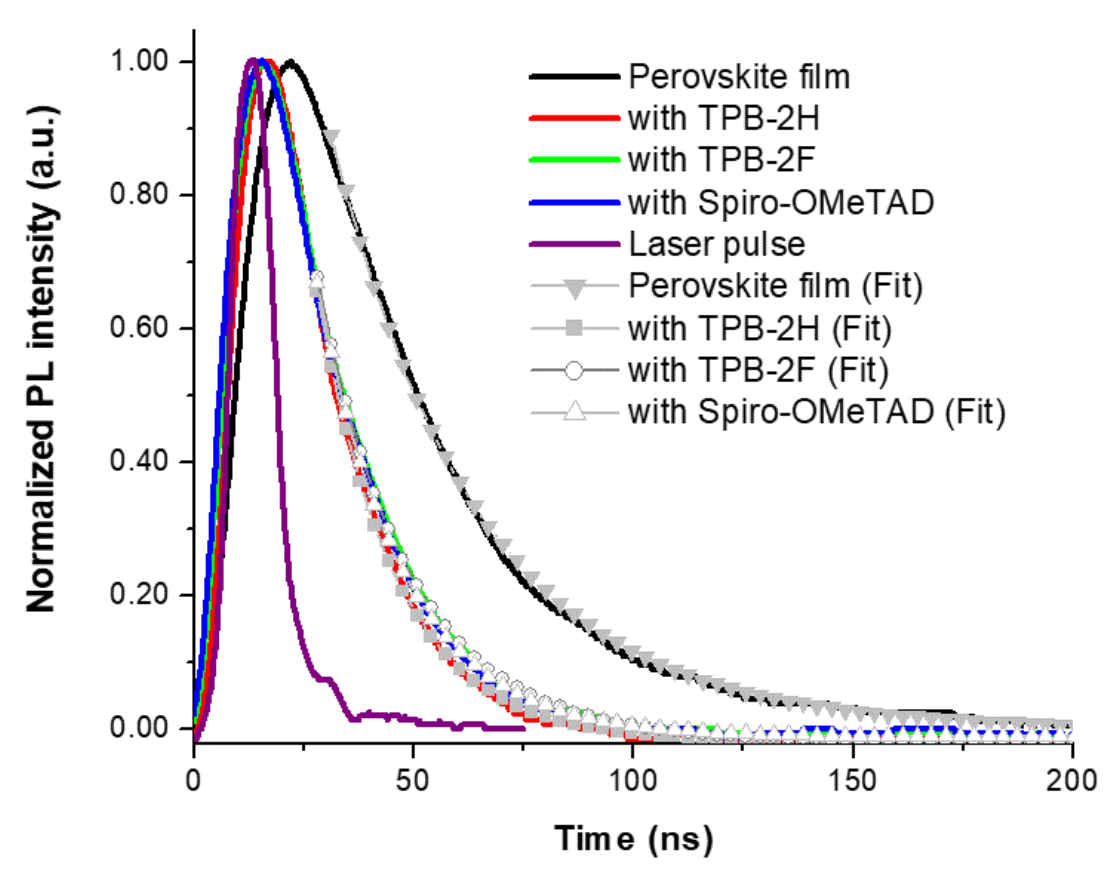

\begin{tabular}{|c|c|c|c|}
\hline Sample & $\tau_{1}(\mathrm{~ns})$ & $\tau_{2}(\mathrm{~ns})$ & $\tau_{\text {average }}(\mathrm{ns})$ \\
\hline Perovskite & $29 \pm 5$ & $41 \pm 5$ & $35 \pm 5$ \\
\hline with TPB-2H & $16 \pm 5$ & $21 \pm 5$ & $19 \pm 5$ \\
\hline with TPB-2F & $18 \pm 5$ & $24 \pm 5$ & $21 \pm 5$ \\
\hline with Spiro-OMeTAD & $18 \pm 5$ & $20 \pm 5$ & $19 \pm 5$ \\
\hline
\end{tabular}

Figure S11. TRPL responses of the perovskite and the perovskite/HTMs films and the extracted decay times.

\section{Synthesis of $\mathrm{TiO}_{2}$ precursor solution}

Titanium oxide precursor solution was prepared by modifying the method previously reported in a literature. ${ }^{2} 2 \mathrm{~mL}$ of titanium (IV) isopropoxide and $0.32 \mathrm{~mL}$ of isopropanol 
were slowly dropped into $14.2 \mathrm{~mL} 0.1 \mathrm{M}$ aqueous nitric acid under vigorous stirring, and the mixture was fluxed at $80{ }^{\circ} \mathrm{C}$ for 8 hours.

\section{E. Device Fabrication}

FTO glass slides $(2.5 \mathrm{~cm} \times 2.5 \mathrm{~cm})$ were patterned and sequentially cleaned with detergent, distilled water, acetone, and isopropyl alcohol in an ultrasonic bath for $15 \mathrm{~min}$ in each step, respectively. The prepared $\mathrm{TiO}_{2}$ precursor colloidal solution was filtered through a $0.45 \mu \mathrm{m}$ syringe filter (Gelman GHP) before spin-coated onto the clean FTO slide glass (at 3,000 rpm for $60 \mathrm{sec}$ ), and sintered at $450{ }^{\circ} \mathrm{C}$ for 1 hour in the air. The deposition was repeated twice to give a smoother electron-transporting layer.

The following two-step preparation method was used for perovskite layer deposition. a 1.2 $\mathrm{M}$ solution of $\mathrm{PbI}_{2}$ in DMF:DMSO (9:1) was preheated at $90{ }^{\circ} \mathrm{C}$ for 12 hours. $\mathrm{The}^{\mathrm{TiO}} \mathrm{T}_{2}$ coated FTO substrate was preheated at $90{ }^{\circ} \mathrm{C}$ on a hotplate for $10 \mathrm{~min}$. The $\mathrm{PbI}_{2}$ solution was filtered through a $0.2 \mu \mathrm{m}$ syringe filter (Gelman GHP) and spin-cast on the substrate at 2,000 rpm for $60 \mathrm{sec}$. Then, the $\mathrm{PbI}_{2}$ coated FTO substrate was post-annealed at $90{ }^{\circ} \mathrm{C}$ on a hotplate for $10 \mathrm{~min}$. Finally, a $0.42 \mathrm{M}$ solution of MAI in IPA was spin-coated on the substrate at 2,000 rpm for $60 \mathrm{sec}$. and a drop of chlorobenzene was applied as an antisolvent for the perovskite layer $15 \mathrm{sec}$ prior to the end of the spin-coating. The sample was post-annealed at $90{ }^{\circ} \mathrm{C}$ for 10 min and dark-brown perovskite layer was formed. For TPB$2 \mathrm{H}$ and TPB-2F, the HTM solution in chlorobenzene $(15 \mathrm{mg} / \mathrm{mL})$ was filtered through a $0.2 \mu \mathrm{m}$ syringe filter (Gelman GHP), followed by spin-coated on the sample at $5,000 \mathrm{rpm}$ for 30 sec. For spiro-OMeTAD as HTM, the solution contains $17.7 \mathrm{~mL}$ of LiTFSI/acetonitrile $(520 \mathrm{mg} / \mathrm{mL})$ solution, $20 \mathrm{~mL} t$-BP, and $0.08 \mathrm{~g}$ Spiro-OMeTAD in 1 
$\mathrm{mL}$ chlorobenzene. The solution was prepared in an Ar environment glove box with a $<0.1$ ppm water level. For static spin-coating of the HTL, $80 \mathrm{~mL}$ of the HTL solution was spread on the substrate before starting spin-coating. Then, the films were spin-coated at 4,000 rpm for $20 \mathrm{~s}$. For dynamic spin-coating of the HTL, $80 \mathrm{~mL}$ of the HTL solution was loaded within the first $2 \mathrm{~s}$ once the substrate started spinning at 4,000 rpm, the entire spin-coating time is 25 s. Lastly, a gold film (100 nm) was coated to complete the PSC fabrication.

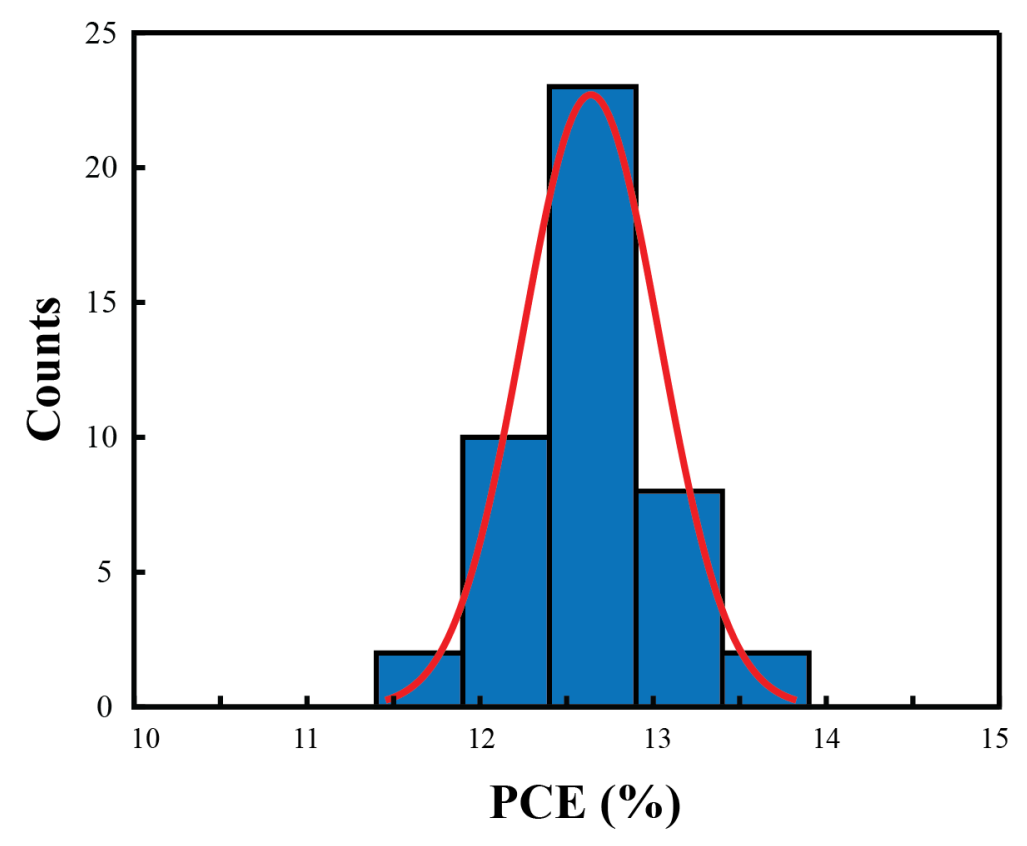

Figure S12. PCE histogram of the TPB-2F based PSCs and fitted distribution curve. 


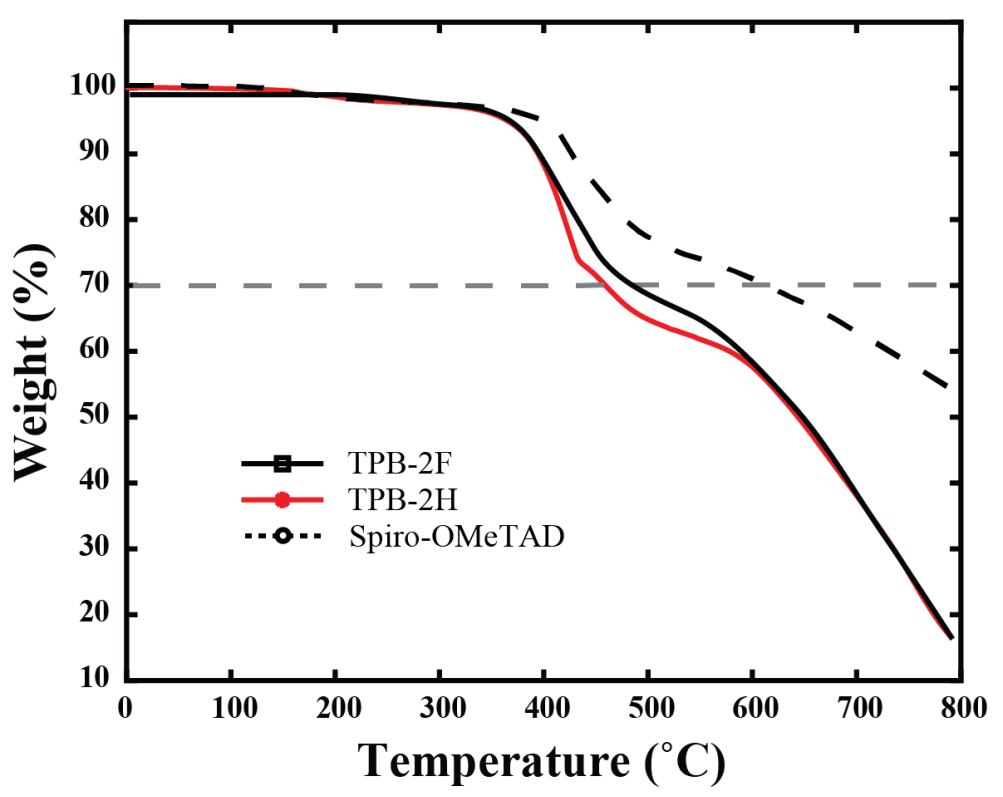

Figure S13. TGA analyses of TPB-2H, TPB-2F and spiro-OMeTAD under Ar atmosphere.

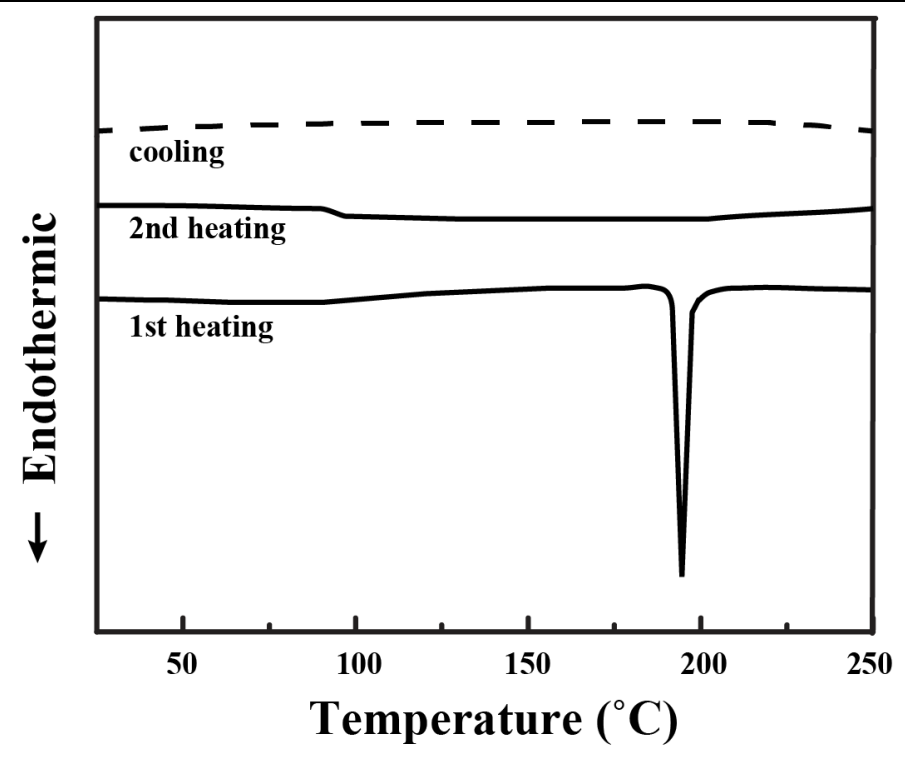

Figure S14. DSC heating cycles of TPB-2F. 
(1) Ikeda, T.; Aprahamian, I.; Stoddart, J. F. Blue-Colored Donor-Acceptor [2]Rotaxane. Org. Lett. 2007, 9, 1481-1484.

(2) Barbé, C. J.; Arendse, F.; Comte, P.; Jirousek, M.; Lenzmann, F.; Shklover, V.; Grätzel, M. Nanocrystalline Titanium Oxide Electrodes for Photovoltaic Applications. J. Am. Ceram. Soc. 2005, 80, 3157-3171. 